\title{
REFLEXÕES ACERCA DAS NARRATIVAS TRANSMIDIÁTICAS APLICADAS À CRÍTICA CINEMATOGRÁFICA NA WEB
}


REFLEXÕES ACERCA DAS NARRATIVAS TRANSMIDIÁTICAS APLICADAS À CRÍTICA CINEMATOGRÁFICA NA WEB

Resumo: O presente artigo objetiva explanar acerca das possibilidades de aplicação das narrativas transmidiáticas no campo da crítica cinematográfica. Uma vez que esta possui como elemento essencial a defesa de argumentos que embasem a opinião do crítico sobre determinada obra, a construção de uma narrativa que utilize diferentes meios mostra-se como uma fonte de comprovação aos argumentos por permitir que diferentes elementos do filme (atuação, direção, fotografia etc.) possam ser mais bem apreciados.

Palavras chave: web; narrativa transmidiática; crítica cinematográfica

REFLEXIONES A CERCA DE LA NARRATIVA TRANSMEDIA APLICADA A CRITICA CINEMATOGRÁFICA

Resumen: El presente artículo tiene por objetivo hacer una explicación a cerca de las posibilidades de aplicación de las narrativas transmedia en el campo de la crítica cinematográfica. Una vez que esta posee como elemento esencial la defensa de argumentos que estén de acuerdo con la opinión de los críticos sobre determinada obra, la construcción de una narrativa que utilice diferentes modos se presenta como un medio de comprobación a los argumentos por permitir que diferentes elementos de la película (actuación, dirección, fotografía, etc.) puedan ser mejor vistos.

Palabras clave: web; narrativa transmedia; crítica cinematográfica

REFLEXIONS OF TRANSMEDIA STORYLETTING APPLIED TO FILM CRITICISM ON WEB

Abstract: the following paper intents to expound the possibilities of applying transmedia storytelling in the field of film criticism. Once film criticism has as an essential element the defense of arguments to lay the foundation of the opinion of the critic about a certain piece, the construction of a narrative which uses different media is seen as a validation font to the arguments because it allows that the different elements from a film (acting, direction, photography etc.) may be better appreciated.

Keywords: web; transmedia storytelling; film criticism 


\section{CONVERGÊNCIA E NARRATIVA TRANSMIDIÁTICA}

A utilização de diferentes recursos multimídia abriu um leque de possibilidades no que diz respeito ao formato da informação veiculada na web. Tais possibilidades de uso podem ser exemplificadas através da questão da convergência midiática, conceito este definido por Silva e Couto (2008) como algo que "expressa a união do telefone, computador, TV a cabo/satélite e empresas de mídia para a invenção e controle do futuro das comunicações". Fragoso (2005), citado por Silva e Couto (2008), descreve melhor essa sinergia de caráter aparentemente apenas tecnológico ao utilizar duas dimensões que enquadram a convergência como um fenômeno de maior alcance. São elas:

A dimensão cultural, de produção e difusão de sentido, capaz de construir significativos para comunidades interpretativas, e a dimensão tecnológica, que transcende as técnicas de transmissão para a construção e consumo de significados e garante os processos de formação técnica que geram ritos sociais compartilhados e aceitos publicamente. (Silva; Couto, 2008, p. 08)

A partir dessas dimensões é possível compreender melhor o conceito de convergência cunhado por Henry Jenkins, que, mais amplo, une-as de maneira sucinta ao afirmar que "por convergência, entendo que seja o fluir do conteúdo através de múltimas plataformas midiáticas, a cooperação entre várias indústrias midiáticas e o comportamento migratório do público dessas mídias" (JENKINS, 2006, p.2, tradução nossa). É dessa forma que se pode falar em uma cultura de convergência, algo que se relaciona não apenas com o desenvolvimento de novas tecnologias, mas sim de que maneira estes influenciam a sociedade em suas vivências. Por essa razão, Jenkins afirma que "a convergência não ocorre através de aplicações midiáticas, não importando o quão sofisticadas elas venham a ser. A convergência acontece nos cérebros de consumidores individuais e através da interação social com outros" (JENKINS, 2006, p.3, tradução nossa).

Ainda segundo o olhar de Jenkins, a cultura de convergência traz consigo um alto caráter de personalização do conteúdo, ocasionando a participação ativa dos consumidores. Tal caráter leva a crer que "melhor que falar sobre produtores de conteúdo e consumidores ocupando papéis separados, agora podemos vê-los como participantes que interagem um com o outro de acordo com um novo conjunto de regras." (JENKINS, 2006, p.3, tradução nossa). Tais 
regras nunca são dispostas em definitivo, conforme Hassapopoulou (2010) assinala ao afirmar que

$\mathrm{Na}$ era digital, as narrativas transmidiáticas redefiniram o conceito de audiência para algo mais interativo e multifacetado. O público não é mais 'apenas público': ele tem a opção de expandir seu papel para o de contribuinte ativo no desenvolvimento de um programa. No entanto [...] o público nunca ganha um privilégio criativo total, e pode mesmo apenas fazer contribuições que sigam os parâmetros estabelecidos pelos produtores e executivos das redes. (Hassapopoulou, 2010, p. 48, tradução nossa)

O próprio Jenkins lida com as limitações de até que ponto a participação ativa dos consumidores interfere nos rumos da narrativa, introduzindo o conceito do game designer Neil Young ao intitular essa participação como 'additive comprehension' e afirmando que "se os criadores não controlam totalmente o que tomamos de suas narrativas transmidiáticas, isso não os impede de tentar moldar nossas interpretações" (JENKINS, 2006, p. 123, tradução nossa).

Para se adaptar a um universo em que as fronteiras entre produtores e consumidores são fluidas, é necessário reformular não apenas o produto em si, mas a forma com que ele é oferecido ao público. Por conta disso, é prudente encarar a convergência tal como Merkin (2010) o faz, ao afirmar que "aos olhos do consumidor, a indústria midiática tem se reorganizado de acordo com os sentidos" (MERKIN, 2010, p.24, tradução nossa). Não se pode ignorar o fato de que "a convergência altera a lógica com a qual as indústrias midiáticas operam e pela qual os consumidores processam as notícias e o entretenimento" (JENKINS, 2006, p.15-16, tradução nossa), e aí se encaixa a questão das narrativas transmidiáticas.

Para Jenkins (2006, p.95), uma história transmidiática se desenrola através de múltiplos suportes midiáticos, com cada novo texto contribuindo de maneira distinta e valiosa para o todo. É dessa maneira que um filme pode expandir o universo de sua narrativa em um jogo ou graphic novel, oferecendo formatos, personagens e situações diferentes do produto original sem a necessidade de uma ordem ou obrigatoriedade de conhecer todos os produtos que transitam nesse mesmo universo; cada um funciona como um ponto de acesso independente ao mundo da narrativa, todos em sintonia para aprofundar e estimular a experiência. Roig (2009) complementa o conceito de narrativa transmidiática ao afirmar que "[...] a narrativa transmedia implica o desenho e a criação de um 
universo próprio, bastante complexo e consistente, com o fim de facilitar seu reconhecimento e sua coerência através de suas diferentes manifestações midiáticas" (ROIG, 2009, p. 245, grifo do autor, tradução nossa). Não se pode ignorar também o viés mercadológico de Merkin (2010) quando sumariza o conceito de narrativa transmidiática ao dizer que "as narrativas transmidiáticas constroem referências narrativas em cada um de seus componentes para dirigir o público através do sistema fechado da franquia - a qual, quando encaradas em sua totalidade, criam a narrativa transmidiática." (MERKIN, 2010, p.28, tradução nossa).

É importante deixar claro que as narrativas transmidiáticas nada tem a ver com a reprodução de um mesmo conteúdo em diferentes meios, e sim com a criação de conteúdos próprios para cada um deles. A redundância pode mesmo ser um fator negativo, conforme afirma Jenkins quando diz que "redundâncias minam o interesse do público e leva ao fracasso das franquias. Oferecer novos níveis de experiências e insights dá novos ares à franquia e ajuda a manter a fidelidade do consumidor." (JENKINS, 2009, p.96, tradução nossa). Além disso, destaca-se o que Janet Murray chama de capacidade enciclopédica que essas narrativas possuem por agregarem tanta informação e possibilitarem o consumo delas tanto quanto possível. Segundo Murray (1997), citada por Jenkins (2009), essas informações "possibilitam que o público compreenda a densidade psicológica e os espaços culturais [representados pelas narrativas modernas] sem deixá-lo desorientado." (JENKINS, 2009, p.116, tradução nossa).

O presente artigo se propõe a fazer uma reflexão acerca do uso de elementos comuns às narrativas transmidiáticas enquanto possibilidades aplicadas à crítica cinematográfica na web. Tal análise faz-se necessária pelo fato de que cada vez mais os recursos próprios da web apresentam chances de expandir o que o tradicional texto de resenha outrora limitou a páginas de jornais e revistas, apesar de ainda ser cedo para afirmar com certeza quais exatos elementos garantem o sucesso na criação de narrativas transmidiáticas. Portanto, levarse-á em conta o que Jenkins (2006) frisou ao afirmar que

[...] Nós ainda não temos um bom critério estético para avaliar trabaIhos que se estendem a múltiplas mídias. Surgiram ainda muito poucas narrativas verdadeiramente transmidiáticas para dar certeza aos produtores de conteúdo midiático em relação ao que se constituiria como o melhor uso desse novo modo de contar histórias, ou para críticos e consumidores saberem como falar profundamente sobre o que funciona ou não nessas franquias. (Jenkins, 2006, p.96-97, tradução nossa) 


\section{A CRÍTICA CINEMATOGRÁFICA}

Seja em um meio tradicional como o impresso ou na web, a crítica cinematográfica se configura basicamente no formato de resenha. Lakatos (2001), citado por Lopes (2006), define esse tipo de texto como sendo "uma descrição minuciosa que compreende certo número de fatos: é a apresentação do conteúdo de uma obra. Consiste na leitura, no resumo, na crítica e na formulação de um conceito de valor" (LOPES, 2006, p.268). Severino (2002) complementa ainda essa conceituação ao delimitar as resenhas como informativa, crítica e crítico-informativa. Segundo o autor, "uma resenha pode ser puramente informativa, quando apenas expõe o conteúdo do texto; é crítica quando se manifesta sobre o valor e o alcance do texto analisado; é crítico-informativa quando expõe o conteúdo e tece comentários" (Severino, 2002, p.131-2, grifo do autor).

Independente do meio em que é veiculada, a crítica cinematográfica possui influência sobre o que é tido como relevante para seus leitores consumirem na hora de ir ao cinema. Não obstante, seja este encarado como arte, entretenimento ou um pouco dos dois, o trabalho dos teóricos e críticos da área é responsável por novos usos e intenções do cinema tanto quanto os próprios realizadores. Sobre o papel do crítico, Godard (1969) afirma que "freqüentar os cine-clubes e a Cinemateca, já era fazer cinema, pois, entre escrever e filmar, há uma diferença quantitativa e, não, qualitativa" (GODARD, 1969, p. 148). Metz (2007) também reconhece o valor da análise fílmica ao dizer que

Sem dúvida, a crítica dos filmes - ou melhor, a sua análise - constitui tarefa essencial: são os cineastas que fazem o cinema, é através da reflexão sobre os filmes de que gostamos (ou de que não gostamos...) que conseguimos alcançar numerosas verdades referentes à arte do filme em geral (Metz, 2007, p. 16)

A contemporaneidade, marcada pela lógica do mercado que supervaloriza o entretenimento, torna a tarefa do crítico ainda mais significativa, pois estes atuam como formadores de opinião e influenciam diretamente o tempo do lazer dos leitores expectadores. Para Youngblood (1970),

[...] O homem é condicionado pelo ambiente em que vive, e esse 'ambiente' para o homem contemporâneo é a rede intermidiática. Nós somos mais condicionados pelo cinema e pela televisão que pela natureza. Uma vez que aceitamos isso, torna-se imediatamente óbvio 
que a estrutura e o conteúdo do cinema popular é um assunto de importância cardinal. (Youngblood, 1970, p. 54, tradução nossa)

Por conta da crescente (embora nem sempre reconhecida) importância do cinema e da crítica cinematográfica, faz-se necessário que a análise fílmica obedeça, na medida do possível, aos preceitos ditados ao longo de sua história. Segundo os teóricos Vanoye e Goliot-Lété (1994), "analisar um filme não é mais vê-lo, é revê-lo e, mais ainda, examiná-lo tecnicamente" (VANOYE; GOLIOT-LÉTÉ, 1994, p.12, grifo do autor). Para tal, faz-se necessário vencer o que os autores chamam de obstáculos de ordem material para melhor estabelecer dispositivos de observação do filme, uma vez que

Enquanto a análise literária explica o escrito pelo escrito, a homogeneidade de significantes permitindo a citação, em suas formas escritas, a análise fílmica só consegue transpor, transcodificar o que pertence ao visual (descrição dos objetos filmados, cores, movimentos, luz etc.) do fílmico (montagem de imagens), do sonoro (músicas, ruídos, grãos, tons, tonalidades das vozes) e do audiovisual (relações entre imagens e sons). (Vanoye; Goliot-Léte, 1994, p. 10)

Além dos obstáculos de ordem material, há também os de ordem psicológica, pois a análise fílmica lida com as significações da obra, de forma que "a descrição e análise procedem de um processo de compreensão, de (re) constituição de um outro objeto, o filme acabado passado pelo crivo da análise, da interpretação" (VANOYE; GOLIOT-LÉTÉ, 1994, p.12). Sumarizando a questão, os autores resumem o objetivo da análise fílmica ao delimitar seu desafio como sendo "reforçar o deslumbramento do espectador, quando merece ficar maravilhado, mas tornando-o um deslumbramento participativo" (VANOYE; GOLIOT -LÉTÉ, 1994, p.13). Tal deslumbramento se relaciona com a noção do espectador consciente tratada por José Rafael de Menezes, segundo o qual o espectador deve ser capaz de encarar uma obra de maneira crítica e de forma que tenha

[...] noção da perspectiva artística do cinema e de que um filme, como lembra Georges Damas, citado por José Rafael de Menezes (op. cit., p.171) expressa as concepções de um diretor, as teses de um cenarista, a atmosfera criada por um decorador, e não a vida mesma, nem a realidade, já que no cinema tudo se acha recriado (Menezes apud Bilharinho, 1996, p. 23) 
Complementa a noção de espectador consciente o efeito de distanciamento citado por Alea como forma de precaver o senso crítico de se embaçar perante a atração que um filme é capaz de exercer em quem o assiste. Para Alea (1984),

O efeito de distanciamento proclamado por Brecht é de fato uma ruptura dentro do processo de identificação e impede o acabamento deste, de modo que o espectador não se entregue totalmente, conservando a lucidez e o sentido crítico [...] Para compreender a realidade objetivamente é necessário separar-se dela, distanciar-se, não estar implicado emocionalmente. Só assim a capacidade de discernimento pode - e deve - ser estimulada pelo espetáculo, de maneira que se descubram novas relações e um novo significado para tudo aquilo que não é familiar (Alea, 1984, p.58-9, grifo nosso).

Stephenson e Debrix (1969) também destacam a necessidade do distanciamento para o crítico desenvolver uma análise fílmica equilibrada. Os autores encaram o ato de assistir a um filme como uma intensa atividade sensorial e intelectual, que envolve um alto nível de subjetividade tanto do espectador quanto do realizador, uma vez que este último "oferece apenas sua experiência que o espectador individual pode ou não aceitar e reconhecer, como correspondendo a algo que ele preza." (Stephenson; Debrix, 1969, p.223). Essa delicada relação é abordada por Stephenson e Debrix quando afirmam que

[...] na realidade, assistir a um filme implica, ou deveria implicar, bastante intensa atividade sensória e intelectual, e em todas as artes o espectador deve dar alguma contribuição para que seja completa a comunicação da experiência do artista. Da mesma forma que com o trabalho do artista, a contribuição do espectador é também em dois níveis, o físico e o mental. (Stephenson; Debrix, 1969, p.218)

Além de Stephenson e Debrix, Mauerhofer (1983) também encara o ato de assistir a um filme como tendo um caráter subjetivo, de fuga da realidade e de experiência individual. De acordo com o autor, tal experiência modifica a sensação de tempo e espaço do espectador, fazendo surgir nele um desejo de ação intensificada ao mesmo tempo que o espectador se torna passivo e anônimo perante a trama que o envolve na tela. Para Mauerhofer, "[...] a fuga voluntária da realidade cotidiana é uma característica essencial da situação de cinema" (Mauerhofer, 1983, p. 376, grifo do autor).

Pelo fato de o crítico não deixar ele próprio de ser espectador, ele enfren- 
ta o dilema de não poder provar a qualidade definitiva de um filme, uma vez que, além de as regras que ditam seu trabalho não serem claras, o nível de subjetividade que envolve a análise é sempre um desafio. Nesse sentido, é de grande ajuda para o desenvolvimento da crítica se aliar a uma contextualização histórica da obra de acordo com suas influências e correntes teóricas, além de relacioná-lo aos aspectos técnicos do fazer cinema.

Analisar um filme é também situá-lo num contexto, numa história. E, se considerarmos o cinema como arte, é situar o filme em uma história das formas fílmicas; Assim como os romances, as obras pictóricas ou musicais, os filmes inscrevem-se em correntes, em tendências e até em 'escolas' estéticas, ou nelas se inspiram a posteriori (Vanoye; Goliot-Lété, 1994, p.23).

Resumindo, o crítico cinematográfico deve ser um espectador consciente e ativo, que saiba enfrentar os obstáculos de ordem material e psicológica, contextualizar a obra historicamente e/ou dentro dos movimentos artísticos em que ela se enquadra, atentar aos aspectos técnicos do filme e ter boa capacidade argumentativa para definir a qualidade de um filme, este encarado como objeto de estudo, e não apenas de lazer. Repensando as qualidades listadas acima, percebe-se que a web nem sempre abriga críticas que respeitem a esses preceitos. Porém, as possibilidades do meio podem dar vazão a um novo tipo de texto, mais completo e argumentativo na medida em que abre espaço principalmente para o uso de hiperligações, elementos multimídia e para a expansão do universo tradicionalmente impresso e fechado da crítica através da narrativa transmidiática.

\section{POSSIBILIDADES TRANSMIDIÁTICAS}

Reno e Gonçalves (2007) avaliam a hipertextualidade como uma característica essencial para ampliar os pontos de vista sobre um determinado assunto na web. Os autores definem hipertexto e relacionam este com o conceito mais geral de hipermídia da seguinte forma:

Hipertexto, segundo Aarseth (1997, p.41-42) é validado por seu dinamismo, interdeterminabilidade, transitoriedade, maneabilidade e funcionalidade. Hipermídia, por sua vez, ganha corpo com Landow (1992, p.15), definindo-a como extensão da noção de texto hipertex- 
tual ao incluir informação visual, sonora, animação e outras formas de informação. (RENÓ \& GONÇALVES, 2007, p. 01)

Santaella (2004), citada por Reno e Gonçalves (2007), complementa ainda que a hipertextualidade modifica o papel desempenhado pelo leitor-internauta na web. Segundo a autora, "com os novos conceitos de autoria e co -autoria, provocadas pelo advento da hipertextualidade, o leitor/espectador não se contenta com a passividade" (Reno \& Gonçalves, 2007, p. 7). Reno e Gonçalves (2007) também levam em conta o papel ativo do leitor perante o hipertexto ao afirmarem que "com o advento da hipertextualidade, o leitor/ espectador passa a ser co-autor da obra, pois a reconstrói no momento da leitura, na escolha de novos caminhos e obtenção de uma nova experiência". (Renó \& Gonçalves, 2007, p. 7).

É através de tal ambiente fluido que a crítica cinematográfica na web pode ir além do texto e utilizar áudio, vídeo, foto e quaisquer recursos para firmar sua posição, uma vez que o texto "transmuta-se em hipertexto, e os hipertextos conectam-se para formar o plano hipertextual indefinidamente aberto e móvel da web" (Lévy, 2008, p. 149). Longe de esta possibilidade ir contra os preceitos da construção da crítica cinematográfica, em verdade ela é prevista pelos teóricos. Vanoye e Goliot-Lété afirmam que "a análise de filme geralmente dá lugar a uma produção escrita, mas pode também conduzir a uma produção audiovisual ou mista" (Vanoye; Goliot-Lété, 1994, p.12, grifo nosso), de maneira que a narrativa transmidiática entra facilmente nesta última categoria.

Para Ribas (2004), o fascínio exercido pela web faz com que o leitor-internauta perca facilmente o foco de atenção, tornando necessária a criação de "estratégias de persuasão e construções criativas e interessantes da narrativa" (Ribas, 2004, p. 11) para que o texto atinja um maior número de leitores. Dessa forma, a narrativa transmidiática surge como possibilidade para uma nova configuração da crítica cinematográfica na web na medida em que a expansão da narrativa para diferentes meios atinge não apenas um maior número de leitores, mas também permite que a crítica os atinja de maneira mais impactante (uma vez que o meio em que é veiculada tem a preferência do leitor). Além disso, esse tipo de narrativa faz com que cada meio tenha a chance de construir um texto que adéqüe seu formato e ferramentas à argumentação típica da análise fílmica. No caso da web, o texto tornado hipertexto, aliado a multi- 
midialidade do meio, enriquece a leitura justamente pelo que o meio oferece (vídeo, imagem, som, links que levam para outros sites que possam validar ou confrontar a opinião ali exposta, informações similares etc.).

Dentre os exemplos de utilização da narrativa transmidiática a serviço da crítica cinematográfica está o site da Revista Veja (http://veja.abril.com.br), que hospeda o blog de cinema da jornalista Isabela Boscov (http://veja.abril.com. br/blog/isabela-boscov/). Boscov atua como editora da Revista Veja e produz críticas cinematográficas tanto para o impresso quanto para a web, adaptando o conteúdo para cada meio e os mantendo como pontos de acesso independentes, tal como Jenkins (2006) considera ideal para a narrativa transmidiática.

Com uma linguagem claramente mais informal e pessoal que no texto de revista, as críticas de Boscov no site da Veja seguem muitos dos preceitos da análise fílmica tradicional. A jornalista em geral elenca características tais como os aspectos técnicos do filme resenhado dignos de nota, desde a fotografia, trilha sonora e atuação, além de revelar a sinopse do filme, contextualizar o enredo e dar o seu veredicto. O diferencial surge aí através do caráter misto da crítica, que permite que o espectador-internauta assista a trechos do filme enquanto acompanha um off explicando a sinopse ou comprovando a beleza estética da fotografia, por exemplo. Tal possibilidade não seria possível na revista, de forma que a aplicação simples da narrativa transmidiática permite não apenas chamar mais atenção dos leitores tradicionais da Veja, mas atrair um público mais abrangente de internautas que nunca leram a revista ou que de outra forma não consumiriam a resenha de um filme por não terem afinidade com a leitura. Ao tornar possível 'assistir a uma resenha', garante-se a imersão de uma nova fatia de consumidores da crítica cinematográfica e a formação de uma nova linguagem.

No entanto, faz-se necessário atentar ao caráter básico do uso da narrativa transmidiática do site da Veja. A identidade visual criada para o blog e para os vídeos não deixam dúvidas de que se trata de um produto da Veja, mantendo a semelhança com o site e com a revista em si no uso da logomarca, das cores e da disposição dos elementos na página. Tal estratégia é prevista na narrativa transmidiática pois auxilia no processo de fixação da marca e da noção de que aquele produto pertence à uma franquia. Porém, o recurso audiovisual é utilizado mais para dar suporte à sinopse da trama que para expor aspectos técnicos listados no decorrer da crítica, perdendo aí a chance de embasar com trechos do próprio filme as argumentações expostas na análise fílmica. A utilização de hiperlinks e ferramentas multimídia a serviço da resenha também 
é feito de maneira tímida, limitando-se a presença de tags, ligações com sites como o Twitter, Orkut e Facebook e arquivo de postagens. A sessão de comentários, que poderia constituir uma linguagem mais ousada pra a crítica através da construção contínua da análise fílmica por conta das opiniões e informações expostas pelos leitores, também deixa a desejar, pois em muitas postagens verifica-se a insatisfação dos leitores-internautas pelo falo de a jornalista não manter um diálogo com as pessoas que comentam no site; perde-se aí a chance de conduzir a uma crítica em aberto, enriquecida constantemente a cada novo ponto de vista exposto e de acordo com o próprio modus operandi da web.

Outro exemplo da utilização da narrativa transmidiática na crítica cinematográfica pôde ser acompanhado através do trabalho do crítico norte-americano Roger Ebert. O site http://www.rogerebert.com funciona desde 2004, atuando por dois anos concomitantemente ao programa de televisão 'At The Movies', estrelado por Ebert e também sobre crítica cinematográfica. Embora o programa televisivo pertencesse a rede $A B C$ e o site de Ebert ter ligação com o jornal 'Chicago Suntimes', a notoriedade do crítico criou uma ponte entre produtos que não pertencem a uma mesma franquia e explicitou outros aspectos da narrativa transmidiática.

Ebert foi pioneiro por ter migrado de um meio a outro, aproveitando muitas de suas potencialidades. A cultura de convergência que abrangeu seu trabalho é responsável pelo fato de que muitos de seus fãs postarem no Youtube trechos de episódios do ‘At the movies' que datam dos anos 1980, trazendo a tona para uma nova geração de cinéfilos as críticas do jornalista e dando um caráter atemporal a elas. Não obstante, alguns dos vídeos são criados e editados pelos fás, muitos deles sendo uma compilação do que o internauta considera os melhores momentos do programa. Tanto quando o caráter de construção do produto em diferentes meios, a narrativa transmidiática lida com essa faceta participativa dos que outrora fizeram parte apenas do conceito de público, mesclando papéis entre estes e os produtores.

Outra característica do trabalho de Ebert que em muitos sentidos se relaciona com a cultura de convergência é o fato de que o 'At the movies' sempre foi apresentado em dupla, com Ebert e outro crítico apresentando diferentes argumentos para a crítica e eventualmente discordando um do outro, cada um apontando livremente seus pontos de vista. No site de Ebert essa postura também se manifesta, mas agora através dos comentários de leitores-internautas. Em entrevista concedida a Frank Tryon e postada em seu site oficial, Henry 
Jenkins (2010) destaca um exemplo dessa cultura participativa essencial às narrativas transmidiáticas que ocorreu no site de Ebert: uma de suas postagens defendia o ponto de vista de que os videogames não poderiam ser uma forma de arte. Após a postagem, o autor recebeu centenas de comentários sofisticados e repleto de argumentações bem embasadas acerca da definição de arte e da estética dos videogames, o que fez o crítico reconhecer as limitações de seu argumento original.

A relação mais próxima entre público e crítico não acontece apenas através dos comentários. O site de Ebert mantém um espaço chamado 'Answer man' no qual é possível mandar e-mails para o jornalista. Outra maneira de entrar em contato é através do perfil de Ebert no Twitter ou Facebook. Há também a opção de assinar a newsletter e receber as resenhas via e-mail, comprar os livros publicados pelo crítico pela internet ou acessar seu blog, publicado pelo site do 'Chicago Suntimes'. Resumindo, há muitas possibilidades de quebrar a barreira antes intransponível entre o formador de opinião e seus leitores. $\mathrm{Na}$ entrevista de Jenkins a Tryon, o teórico considera fascinante a transformação de Ebert através do uso de mídias sociais.

\section{CONSIDERAÇÕES FINAIS}

A narrativa transmidiática apresenta diversas oportunidades para uma nova constituição da crítica cinematográfica. Tais possibilidades abrangem desde o processo de identificação entre crítico e público, passando pela mescla entre os papéis de um e de outro e a possibilidade de utilizar diferentes meios tanto para chamar a atenção do público quanto para apresentar argumentos que embasem satisfatoriamente a análise fílmica. Porém, como se pode observar com os exemplos citados, o uso desse tipo de narrativa é relativamente novo e ainda está se desenvolvendo. Ao contrário dos filmes em si, cujas tramas já se desenrolam em jogos, sites e campanhas de publicidade viral com certa naturalidade (vide as produções norte-americanas 'Batman - o cavaleiro das trevas', de Christopher Nolan, ou 'Alice no país das maravilhas', de Tim Burton), a crítica relativa à Sétima Arte ainda não acompanha tamanhas inovações.

Por conta da recente atenção que as narrativas transmidiáticas vem recebendo, ainda é cedo para dizer com certeza quais dos seus usos são os mais apropriados tanto para a crítica cinematográfica quanto para qualquer outro produto. Seu futuro dependerá de experiências futuras no cinema, na web, na 
TV e em outros meios, conforme acredita o próprio Jenkins. O estágio atual ainda é de transição entre as mídias tradicionais e novas e o entrelaçamento de ambas acontece gradualmente. Birketrts, Thornburn e Jenkins (2004), citados por Bakioğlu (2009), corroboram com esse pensamento ao afirmarem que “tecnologias emergentes desestabilizam temporariamente as relações entre meios pré-existentes e iniciam uma era de transição marcada pela convergência de diferentes formas, que criam uma ponte entre tecnologias, formatos e públicos antigos e novos" (BAKIOĞLU, 2009, p. 338, tradução nossa).

Até o presente momento, a característica de maior destaque resultante do uso das narrativas transmidiáticas na crítica cinematográfica é a significante participação do público. Este comenta, contesta, contrapõe ou fundamenta melhor pontos de vistas inicialmente expostos e se mesmo assim não se satisfaz, produz ele próprio um conteúdo que o agrade e divulga principalmente via web. Na busca pelos consumidores, mesmo os críticos cinematográficos já compreenderam que essa participação é essencial para garantir leitores, e que estes têm sim um papel a desempenhar na construção de uma boa análise.

Esse novo modelo de crítica cinematográfica em constante transformação faz parte do hall de experimentos com a narrativa e não devem ser vistos como uma moda passageira ou uma inovação que perderá força com o passar do tempo. Pelo fato de a web ser um meio que se populariza cada vez mais na sociedade contemporânea e a sinergia entre meios surgir como uma tendência forte no campo da comunicação, Jenkins (2006) destaca a necessidade de não ignorar essas novas formas narrativas:

A maioria dos críticos de cinema é ensinada a pensar em termos de estruturas narrativas muito tradicionais. Mais e mais, eles são ensinados a falar do colapso da narrativa. Devemos levantar suspeitas quanto essas afirmações, uma vez que é difícil imaginar que o público tenha perdido mesmo o interesse nas narrativas. Elas são básicas em todas as culturas humanas, o meio principal pelo qual estruturamos, compartilhamos e damos sentido à nossas experiências em comum. Muito pelo contrário, presenciamos o crescimento de novas estruturas narrativas, que criam complexidade ao expandir o alcance das possibilidades narrativas ao invés de dar um único caminho com começo, meio e fim. (JENKINS, 2006, p.118-119, tradução nossa)

Os críticos que optam pelo modelo tradicional de análise fílmica, de preceitos e métodos já bem delimitados pela literatura da área, podem encontrar na 
narrativa transmidiática muito mais que o aparente caos de uma 'crítica aberta', fragmentada e com outras vozes se manifestando a partir do texto original. Essa abertura dá espaço para o desenvolvimento crítico do leitor (ou espectador, ou internauta, ou todas essas opções), que recebe indubitavelmente o aval de ter uma opinião sobre o objeto de análise, uma vez que "os fragmentos existem para que os consumidores possam fazer conexões entre eles ao seu próprio tempo e seguindo seus próprios caminhos" (JENKINS, 2006, p.199, tradução nossa). Reno (2007) também frisa o papel ativo do leitor em frente à possibilidade de atingir tal autonomia ao encara um conteúdo que "pode ser 'acessado' de acordo com grau de detalhamento procurado pelo leitor” (RENÓ, 2007, p.03).

Longe de ir contra o próprio conceito da crítica cinematográfica, a aplicação da narrativa transmidiática corrobora para o papel que elas desempenham na sociedade. Ao oferecer o máximo de pontos de vistas possíveis sobre determinada obra, é o leitor que dá o seu veredicto, que pode ou não concordar com o autor da crítica baseando-se nas evidências e argumentos apresentados. Para Stephenson e Debrix, "talvez seja indício de uma riqueza em uma obra de arte provocar um conflito de julgamentos críticos e também despertar uma forte atração sobre vários aspectos" (Stephenson; Debrix, 1969, p. 226). Dessa forma, um confronto crítico proporcionado pela narrativa transmidiática parece benéfico para aguçar a curiosidade do leitor.

\section{REFERÊNCIAS}

ALEA, Tomás Gutiérrez. Dialética do Espectador. São. Paulo: Summus, 1984.

BAKIOČLU, Burcu S. The business of storytelling: production of works, poaching communities, and creation of story worlds. http://www.palefirer.com/business_story_telling.pdf. Acesso em: 15 de janeiro de 2011.

BILHARINHO, Guido. Cem anos de cinema. Uberaba: Instituto Triangulino de cultura, 1996. BOSCOV, Isabela. Cinema. http://veja.abril.com.br/blog/isabela-boscov/. Acesso em: 8 de janeiro de 2011.

EBERT, Roger. http://rogerebert.suntimes.com/. Acesso em: 9 de janeiro de 2011.

GODARD, Jean-Luc. Montagem de textos, 1952-1967. In: GRÜNNEWALD, José Lino. A idéia do cinema. Rio de Janeiro: Civilização Brasileira, 1969. p. $137-152$.

HASSAPOPOULOU, Marina. Spoiling Heroes, Enhancing our viewing pleasure: NBC's Heroes and the re-shaping of the televisual landscape. In: URBANSKI, Heather. Writing and the Digital Generation: Essays on New Media Rhetoric. Jefferson: McFarland \& Co., 2010. 
JENKINS, Henry. Convergence culture: where old and new media collide. New York: New York University Press, 2006.

JENKINS, Henry. Confessions of an aca-fan: the official weblog of Henry Jenkins. http:// henryjenkins.org/2010/07/reinventing_cinema_an_intervie.html. Acesso em: 13 de janeiro de 2011.

LÉVY, Pierre. Cibercultura. São Paulo: Editora 34, 2008.

LOPES, Jorge. O fazer do trabalho científico em ciências sociais aplicadas. Recife: Ed. Universitária da UFPE, 2006.

MERKIN, Andrew. The management of transmedia production in an era of media and digital convergence. http://dspace.mit.edu/handle/1721.1/59144. Acesso em: 29 de novembro de 2010.

METZ, Christian. A significação do cinema. $2^{a}$ edição. São Paulo: Perspectiva, 2007.

RENÓ, Denis Porto; GONÇALVES, Elizabeth Moraes. Hipertexto e montagem audiovisual: reflexões e novos formatos. http://encipecom.metodista.br/mediawiki/index.php/Hipertexto_e_montagem_audiovisual:_reflex\%C3\%B5es_e_novos_formatos. Acesso em: 23 de dezembro de 2010.

RIBAS, Beatriz. Características da notícia na Web: considerações sobre modelos narrat ivos. Disponível em: <http://www.facom.ufba.br/jol/pdf/2004_ribas_sbpjor_salvador_modelosnarrativos.pdf>. Acesso em: 23 de dezembro de 2010.

ROIG, Antoni. Cine en conexión: producción industrial y social en la era cross-media. Barcelona: UOC Press, 2009.

SILVA, Valdirene Cássia; COUTO, Edvaldo Souza. Convergência cultural-midiática: as tecnologias e a fluidez da juventude na cibercultura. http://www.cult.ufba.br/enecult2008/14165. pdf. Acesso em: 16 de novembro de 2010.

VANOYE, Francis; GOLIOT-LÉTÉ, Anne. Ensaio Sobre A Análise Fílmica. Campinas, SP: Papirus, 1994.

YOUNGBLOOD, Gene. Expanded cinema. New York: P Dutton\&Co, 1970.

RECEBIDO EM: 09/11/12

ACEITO PARA PUBLICAÇÃO: 25/11/12 


\section{Susy Elaine da Costa Freitas}

Possui graduação em Letras - Língua Inglesa pela Universidade Federal do Amazonas (2007) e Comunicação Social, habilitação Jornalismo, pela Universidade Federal do Amazonas (2011). É mestranda do Programa de Pós-graduação em Ciências da Comunicação da Universidade Federal do Amazonas (PPGCCOM/ Ufam). É integrante do Mediação - Grupo de Pesquisa em Semiótica da Comunicação. Atua principalmente nos seguintes temas: web, cinema, crítica e mídias digitais. 